\title{
Study on the decoupling effect of energy consumption and economic growth in the construction industry of Guangxi (People's Republic of China) from the perspective of the circular economy
}

\author{
Fuzhou Luo ${ }^{1} \cdot$. Xing $\mathrm{Li}^{1} \odot$. Cong Peng ${ }^{2}$
}

Received: 23 September 2019 / Accepted: 29 April 2020 / Published online: 6 May 2020

(c) Springer Nature Switzerland AG 2020

\begin{abstract}
Based on relevant data of the Guangxi construction industry from 2008 to 2016, including the regional GDP, the construction industry GDP, the energy consumption in the construction industry, and other indicators, this study analysed the relationship between the energy consumption in the construction industry and economic growth. The Tapio decoupling model and ecological efficiency evaluation model were applied to analyse the above data. Empirical tests revealed that there exists a weak decoupling relationship between the energy consumption and economic growth in the construction industry of Guangxi. Despite the weak decoupling relationship, the ecological efficiency value is only 0.1012 . This result proves that the development level of the circular economy in the construction industry of Guanxi is below the average level, and the sustainable utilization of energy is insufficient. At the end of this article, based on the decoupling effect and production efficiency from 2009 to 2016 , suggestions are formulated, including prioritizing the development of the construction industry and increasing the economic input to promote industrial upgrading.
\end{abstract}

Keywords Circular economy · Decoupling effect · Value stream · Ecological efficiency

JEL Classification Q01·Q56

Mathematics Subject Classification 91B76

\section{Introduction}

After 40 years of rapid development, China has become the largest energy consumer in the world while growing into an economic giant. Industrialization has created unprecedented wealth along with irreparable ecological damage. The new concept of green development advocates a green, low-carbon, circular, and sustainable way of production and living while strengthening the cooperation in ecological protection and establishing an ecological civilization [1]. According to the environmental and new development concept of practising green development, which advocates a green, low-carbon, circular and sustainable production approach and lifestyle, thereby strengthening the cooperation in ecological environment protection and the establishment of an ecological civilization, domestic and foreign scholars have also conducted in-depth discussions and studies on economic growth and environmental issues. Among them, the construction industry, as an essential industrial sector with high consumption and carbon emission levels, is a critical area of research. The fifth assessment report of the

$\triangle$ Xing Li, shinelixing@hotmail.com | ${ }^{1}$ School of Management, Shaanxi Province, Xi'an University of Architecture and Technology, Beilin District, No. 13 Yanta Road, City of Xi'an 710055, People's Republic of China. ${ }^{2}$ Department of Civil Engineering, Guangxi Vocational College of Water Resource and Electric Power, City of Nanning, People's Republic of China. 
Intergovernmental Panel on Climate Change (IPCC) reports a total of 365 billion metric tonnes of carbon emissions due to the fossil fuel and cement utilization in the construction industry [2], which confirms the environmental impact from the energy consumption and carbon emissions of building-related aspects, including building materials and manufacturing and construction processes.

In industrial and regional development, researching the carbon emissions in the construction industry against the background of economic growth greatly influences the examination of the practices and methods of the industrial recycling economy. As one of the pillar industries of the national economy, the construction industry should be regarded as a key industry for sustainable development and circular economy attainment. It is of considerable importance to focus on the relationship and effect between energy consumption and economic growth in the construction industry.

The remainder of the study is organized as follows: Sect. 2 reviews the literature. Section 3 explains the theory and methodology adopted for analysis. Section 4 presents the discussion, and Sect. 5 concludes the article by providing conclusions and policy recommendations.

\section{Literature review}

In terms of previous research and achievements, scholars at home and abroad have mainly adopted the carbon emission level as an evaluation index of energy consumption and have investigated its relationship with economic growth. Ugur Soytasa's primary research was on the degree of correlation and causal relationship between Turkey's macroeconomic growth and the carbon emissions generated by the energy consumed in the production process, and they reported a notable causal relationship between carbon emissions and energy consumption based on the Granger causality test [3]. Nevertheless, through cointegration and Granger causality tests of the relation between India's power supply and GDP from 1970 to 2006, Sajal Ghosh obtained the opposite result whereby no causality was observed between national economic growth and power supply [4]. With the Multi-Criteria Decision Analysis (MCDA) methodology, Imran Khan analysed 19 indicators in the social, environmental, and economic dimensions to address the lack of consideration of sustainable development in Bangladesh's 2016 Power System Master Plan (PSMP) [5]. Balsalobre-Lorente et al. [6] found that natural resources, economic growth, and renewable electricity are significant determinants of $\mathrm{CO}_{2}$ emissions. Wang et al. [7] reported a weak decoupling between the economic growth and energy consumption in most regions of China and conducted Markov chain modelling to predict China's carbon intensity by 2020 , and they established a quantitative relationship between economic growth and energy structure. Mohiuddin et al. [8] used Pakistan panel data from 1971 to 2013 to demonstrate that the energy production from oil (EPL) and energy production from coal (EPC) exert an adverse effect on carbon dioxide emissions, whereas the energy production from gas (EPG) and GDP imposes a positive impact. The Kuznets curve hypothesis is also currently used to describe the relationship between economic growth and energy consumption [9]. Studies incorporated the resource rent into previous carbon emission models, and the results showed that there is a negative balance between $\mathrm{CO}_{2}$ and available urban resource consumption, both in the long and short terms [10]. The reason why developed countries are less vulnerable to climate change is their high economic, governance, and social adaptation readiness [11]. Furthermore, the international commitment from developed countries to developing countries is fundamental [12]. Evidence indicated that the relation between energy consumption and economic growth exhibits a U-shaped pattern in the long run [13].

Hu et al. [14] applied the TodaYamamoto program to analyse the causal relationship between China's energy consumption and economic growth, as well as its carbon emissions, and concluded that economic growth and energy consumption increased the carbon dioxide emissions, while the increase in carbon dioxide emissions did not necessarily correspond to economic growth or an increase in energy consumption. Zhang et al. [15] focused on Shaanxi Province as the first batch of low-carbon pilot provinces and adopted the economic growth and energy consumption indicators of Shaanxi Province from 2000 to 2011 to calculate the decoupling elasticity coefficient. The degree of correlation between economic growth revealed that the degree of decoupling between the economic growth and energy consumption in the construction industry in Shaanxi Province was developing in a positive direction, indicating that the carbon emissions in the construction industry in Shaanxi Province were controlled to a certain degree. Feng et al. [16] utilized the logarithmic mean Divisia index (LMDI) factor decomposition model to decompose and analyse the carbon emissions in China's construction industry from 2004 to 2011 and not only determined the carbon emissions fluctuations at different stages of China's construction industry but also calculated the results of decoupling effects in various regions. Certain provinces were in the weak decoupling state of carbon emissions and remained optimistic about the complete decoupling of carbon emissions from construction industry output growth in the future.

A large number of studies have examined the relationship between energy consumption and economic growth, providing evidence that economic growth exerts a positive 
or negative one-way impact on energy consumption, or there exists a feedback causal relationship between these two aspects [17]. In contrast, other studies indicated no causal relationship. The contribution of this study to the existing literature is as follows: This is the first study to examine the relationship between economic growth and energy consumption in the construction industry from the perspective of the circular economy [18]. Second, in contrast to previous studies, the decoupling model is combined with the ecological efficiency to evaluate the lowcarbon construction industry. Finally, this study chooses China's particular regional location with its national characteristics of international trade and economic cooperation. This study can help decision-makers formulate more informed decisions on the sustainable development of the construction industry in developing countries [19].

\section{Theory and methodology}

\subsection{Circular economy}

The so-called circular economy originated from the spaceship theory in the 1960s by Kenneth E. Boulding. This economic theory states that the Earth system as a whole is similar to a spacecraft in space, without the burden of energy consumption for production, with the limited resources running out sooner or later over the journey. In addition, in the process of resource depletion, large amounts of waste are produced, thereby affecting the original ecosystem and even creating a toxic environment, which will destroy the original ecosystem of the spacecraft, causing collapse [20]. To prevent this from occurring, many experts and scholars proposed the theoretical system of the circular economy ideology shifting the economic growth model from a linear consumption open model to a cyclic ecological production model and converted the open linear model with a large amount of waste into a closed-loop cycle [21].

At present, the proposed sustainable economic development model of China is based on the theoretical basis of the circular economy [22]. Furthermore, the construction industry, as an essential raw material production and processing sector, is fully accounted for. The construction of urban infrastructure and the improvement of the material living standards of the population cause a series of building production needs, which increase the energy consumption of the production of raw building materials and products and buildings themselves, thus imposing an enormous pressure on the ecological environment [23].

From 2009 until now, through the review of relevant documents and the statistical calculation of resource data, it is determined that the overall theoretical research of the circular economy in China has not yet established a complete set of systems [24], nor has a valid circular economic path been adopted by the industry to conduct integration and planning, which is in the drifting state. Many theoretical research aspects need to be deepened and integrated [25]. Typical circular economy research primarily evaluates the ecological efficiency, such as the steel industry circular economy research based on the circular economy efficiency and quality [26]. The establishment of an economic efficiency evaluation index as part of dynamic and static evaluation involves the construction of a quality evaluation system, which affects the relationship between research and environmental assessment. In view of evaluating the decoupling effect of energy consumption and economic growth, this paper examines the circular economy of the construction industry, and it also constructs the optimal path according to the decoupling situation in the region [27]. Figure 1 shows the relevant circular economy relations.
Fig. 1 The circular power system in the construction industry from the perspective of the circular economy

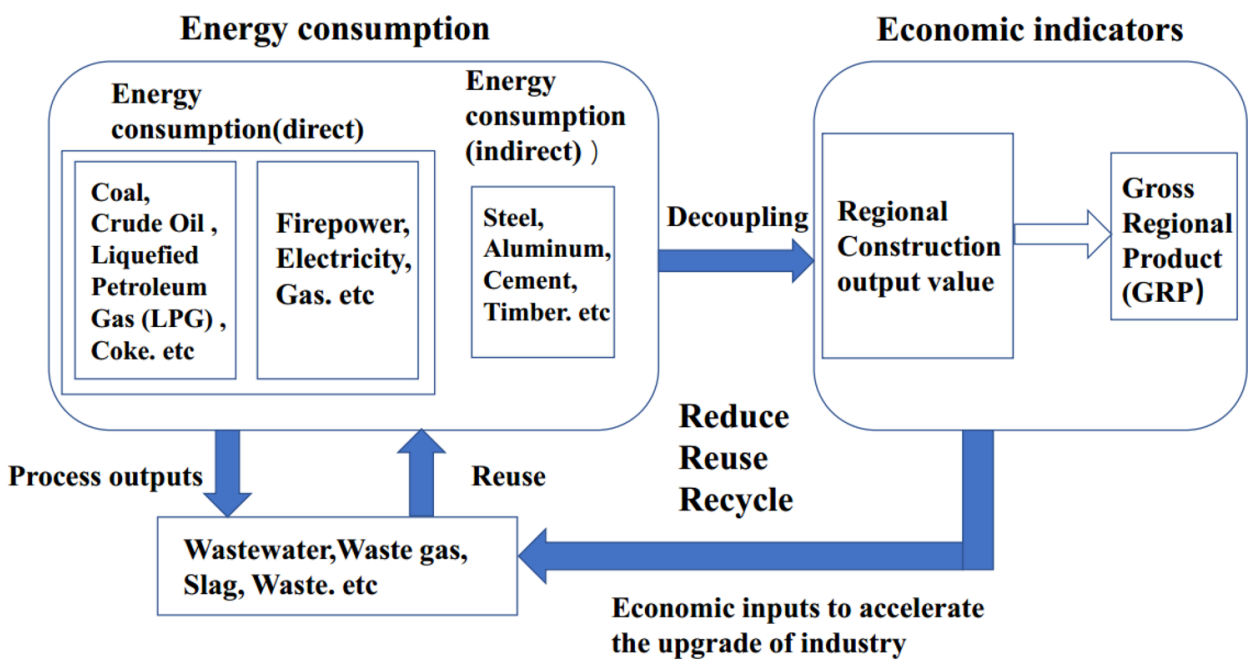

SN Applied Sciences A SPRINGER NATURE journal 
From the perspective of the value flow path, it follows that energy consumption (input) drives the growth of economic indicators. Nevertheless, the optimal state is that of strong decoupling, namely, the growth (decline) of economic indicators is completely independent of the increase (decrease) in energy consumption. This can be achieved by increasing the financial investments in industrial upgrading, improving the production efficiency, utilizing various types of wastewater and waste gas, and generating resource-based products through technology. Hence, renewable resources (recycling and resource recovery) can be maintained. It is valid to form a virtuous cycle in each process of the construction industry. Decoupling energy consumption from economic indicators can produce effective feedback. The value flow of this industry and economic structure fully reflect the closed-loop idea of the circular economy.

\subsection{Tapio decoupling model}

The concepts and theoretical basis of decoupling were proposed by the International Organization for Economic Cooperation and Development (OECD) [28] in 2002 in the research on environmental quality and the interactional relationship between inhibiting environmental quality damage and promoting macroeconomic development. Moreover, this concept has been adopted by an increasing number of scholars and experts, e.g., in the analysis and monitoring of a certain industry or region and even in the determination of the correlation between a country's economic development and environmental damage based on the decoupling index. The decoupling theory refers to the degree of environmental damage caused by resource consumption, which does not always exhibit a tendency of increasing with increasing economic development, and an inverse trend can occur. Its practical significance is that economic growth does not necessarily depend on the consumption of a large amount of energy; in other words, energy consumption may occur that is disproportionate to the degree of economic growth, or energy consumption can even be reduced with increasing economic growth. This phenomenon is consistent with the original concept of a circular economy, which refers to decreasing the degree of environmental damage and pressure on the ecosystem while ensuring economic growth. According to the Tapio decoupling theory and the definition of the decoupling elastic value, the decoupling states are divided in the eight states listed in Table 1 [29].

The above indicators demonstrate that to achieve the ideal state of the circular economy and the goal of the lowcarbon economic era, the most ideal state is the strong decoupling of economic growth and energy consumption, namely, energy consumption should decrease with increasing economic growth (elastic value e $<0$ ).

This paper concentrates on the causal chain relationship of energy consumption-regional construction growth-regional economic growth, which follows the micro-meso-macro path. The well-defined decoupling models are as follows:

1. Industrial energy decoupling coefficient

$$
D E(\text { coupling elasticity })=M \times N \frac{E I_{J}}{G l_{J}} \times \frac{G I_{J}}{G l}=\frac{E I_{J}}{G l}
$$

The above refers to the ratio of the elasticity of the energy consumption index $\left(\mathrm{EI}_{\mathrm{J}}\right)$ to the economic growth index (Gl) of the construction industry in a particular region, which reflects the degree of decoupling of energy consumption and economic growth.

2. Energy decoupling elasticity of the construction industry

$$
M=E I_{J} / G I_{J}
$$

Table 1 The eight different decoupling states of the Tapio

\begin{tabular}{|c|c|c|c|}
\hline Decoupling state & $\begin{array}{l}\text { Value of the decou- } \\
\text { pling elasticity }\end{array}$ & Energy consumption & Economic growth \\
\hline \multicolumn{4}{|l|}{ Negative decoupling } \\
\hline Expansive negative decoupling & $\mathrm{e}>1.2$ & Increase (+) & Increase (+) \\
\hline Weak negative decoupling & $0<\mathrm{e}<0.8$ & Decrease (-) & Decrease (-) \\
\hline Strong negative decoupling & $\mathrm{e}<0$ & Increase (+) & Decrease (-) \\
\hline Recessive decoupling & $\mathrm{e}>1.2$ & Decrease $(-)$ & Decrease $(-)$ \\
\hline \multicolumn{4}{|l|}{ Decoupling } \\
\hline Weak decoupling & $0<\mathrm{e}<0.8$ & Increase (+) & Increase (+) \\
\hline strong decoupling & $\mathrm{e}<0$ & Decrease (-) & Increase (+) \\
\hline \multicolumn{4}{|l|}{ Connection } \\
\hline Growing connection & $0.8<\mathrm{e}<1.2$ & Increase (+) & Increase (+) \\
\hline Decreasing connection & $0.8<\mathrm{e}<1.2$ & Decrease (-) & Decrease (-) \\
\hline
\end{tabular}
decoupling model 
This refers to the ratio of the energy consumption index $\left(E I_{\jmath}\right)$ to the growth of the output value $\left(G I_{\jmath}\right)$ in the construction industry, which reflects the degree of decoupling of the energy consumption within the industry and the growth of the industry output.

3. The elasticity of industrial decoupling

$$
N=G I_{J} / G l
$$

The above refers to the ratio of the industry output $\left(\mathrm{Gl}_{\mathrm{J}}\right)$ to the total output of a region $(\mathrm{Gl})$.

4. Economic growth index

This refers to the relative amount of economic growth, by assessing the difference between two consecutive years. To avoid unnecessary influences and deviations on the calculation results caused by the unit and magnitude of the original data, the underlying data are nondimensionalized first in the decoupling model calculation, which implies that in terms of the raw data of a certain year, the raw data of that year is set to 1 . Moreover, the relative calculation amount depends on the GDP growth in the subsequent years with the aforementioned year as the basis, i.e.:

$$
G I_{n}=1+\frac{G D P_{n}-G D P_{2008}}{G D P_{2008}}
$$

5. Energy consumption index

The above refers to the increasing relative amount of energy consumption, as mentioned above, for the sake of avoiding unnecessary impacts and deviations, and the original data are nondimensionalized, i.e.:

$$
E I_{n}=1+\frac{E C_{n}-E C_{2008}}{E C_{2008}}
$$

\subsection{Ecological efficiency evaluation modelling}

Based on the OEDC's definition of the ecological efficiency, the calculation equation of the production efficiency is defined as follows:

$E E=\frac{\left(\alpha G D P_{P E C}+\beta C P_{C I}\right) \times \lambda}{\alpha E I+\beta P I}$

where $\mathrm{EE}$-ecological efficiency (Eco-efficiency); $\mathrm{GDP}_{\mathrm{PEC}}$ $\mathrm{GDP} /$ energy consumption per tonne; $\mathrm{CP}_{\mathrm{Cl}}$-investment in pollution control projects in the current year; El- energy consumption index;
$\mathrm{Pl}$-production input index; $\alpha$ and $\beta$-weight coefficients, and in this paper; $\alpha=\beta=0.5$ to account for the impact of balancing the energy input and output on the economy; and $\lambda$ ratio of the GDP as the energy consumption per tonne to the proportion of investment in pollution control projects of the construction industry.

Based on the relationship between the GDP of the construction industry and the gross regional product (GRP) of Guangxi, the $\lambda$ values are listed in Table 2.

The research model has a wide range of applicability. By simply adjusting the indexes in the decoupling model equation and the ecological efficiency equation, they can be applied to different industries, such as the steel industry and the construction industry in different regions, such as Thailand.

\section{Discussion}

\subsection{An Overview of the current situation in Guangxi (PRC)}

Guangxi is located in Southwest China, one of the five ethnic autonomous regions in China, and is the permanent host of the China-ASEAN Exposition (CAEXPO). It plays a vital role in the economic and trade exchange with Southeast Asian countries. According to 2016 statistics, the GDP of Guangxi ranked 17th among 31 provinces and cities in China, of which the gross output of the construction industry ranked 20th, and the proportion of the construction industry output ranked 24th. Guangxi is a crucial hub area for the energy restructuring of China [30].

In this study, we consider that the current economic development of Guangxi is a high-energy consumption model, which consumes a large amount of expensive energy. The characteristic of this mode is the promotion of a rapid development of the economy, which completely depends on a high resource consumption. In the long run, the disadvantages of this development model will gradually emerge, thereby causing the social ecosystem to rapidly deteriorate in a short time, which will result in a series of social problems, while the industrial and regional economies, and even the Chinese economy, will fall into a cycle of a high input with a low output. Therefore, it is necessary to establish the circular economic development model characterized by the cycle of a low input with a high output.

Table 2 Values of $\lambda$

\begin{tabular}{llllllllll}
\hline Year & 2008 & 2009 & 2010 & 2011 & 2012 & 2013 & 2014 & 2015 & 2016 \\
\hline$\lambda$ & 0.11 & 0.12 & 0.13 & 0.14 & 0.15 & 0.16 & 0.17 & 0.18 & 0.19 \\
\hline
\end{tabular}




\subsection{Analysis of the energy consumption and economic growth of the construction industry}

In 2008, the Development Planning of the Guangxi Beibu Gulf Economic Zone was approved by the state council, which was a major strategic decision by the central committee of the Communist Party of China (CPC) and the state council to improve the regional economic layout and promote coordinated development and open cooperation across China after the strengthening of the western development strategy [31]. Owing to this policy, the economy of Guangxi was granted a great opportunity for overall economic development relying on the success of the Beibu Gulf Economic Zone. After the policy implementation, the economy of Guangxi developed very rapidly, while a quantum jump in the total energy consumption occurred. Based on data consistency and stability, this paper analyses data from 2008 to 2016 relevant to the economic development of Guangxi by consulting relevant data sources and literature. As obtained from the Guangxi Statistical Yearbook and the China Energy Statistical Yearbook, the related energy and economic indices of the Guangxi construction industry from 2008 to 2016 are listed in Table 3.

The above data and corresponding chart reveal the economic and construction industry growth in Guangxi from 2008 to 2016. Figure 2 shows that the growth of the output of the local construction industry conforms to the local economic growth to a certain degree, which is relatively similar to the growth rate.

However, based on the energy consumption curve in Fig. 3, a similar increase relation between the overall energy consumption and economic growth of Guangxi is observed, indicating that the overall economic growth is accompanied by an increase in energy consumption. In 2015, the growth rate of energy consumption in the

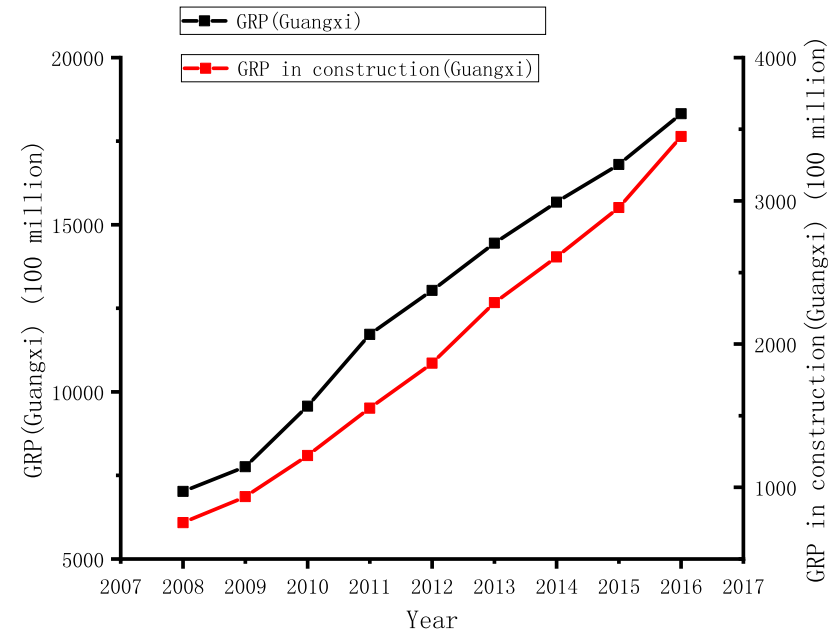

Fig. 2 Line chart of the GRP and GRP in the construction industry in Guangxi from 2008 to 2016

construction industry surpassed that of the total energy consumption. However, the output level of the construction industry in the same year did not sharply increase, indicating that the increase in energy consumption did not promote economic growth. In contrast, it can be assumed that the increases in the output level of the construction industry and the GDP of Guangxi in that year did not necessarily depend on an increase in energy consumption, which supports the possible realization of the low-carbon goal of the circular economy.

According to calculations based on the above data and equations, Table 4 is generated.

According to the calculation results listed in Table 4, it is found that the energy decoupling elasticity values of the construction industry are all smaller than 1 and exhibit a decrease trend year by year. According to the causal chain of the construction industry-construction industry output level—GRP—energy consumption, with the use of the

Table 3 List of the regional GRP, construction industry GRP, regional energy consumption and energy consumption in the construction industry of Guangxi Province, PRC

\begin{tabular}{lllll}
\hline Year & GRP (100 million RMB) & $\begin{array}{l}\text { GRP of the construction } \\
\text { industry }(10 \text { thousand } \\
\text { RMB) }\end{array}$ & $\begin{array}{l}\text { Regional energy consumption } \\
(10 \text { thousand tonnes standard } \\
\text { coal) }\end{array}$ & $\begin{array}{l}\text { Energy consumption in the construction } \\
\text { industry (10 thousand tonnes standard } \\
\text { coal) }\end{array}$ \\
\hline 2008 & 7021 & $7,532,102$ & 6497 & 41.45 \\
2009 & 7759.16 & $9,343,756$ & 7075 & 35.9 \\
2010 & 9569.85 & $12,223,126$ & 7919 & 37.14 \\
2011 & $11,720.87$ & $15,530,712$ & 8591 & 40.83 \\
2012 & $13,035.102$ & $18,670,580$ & 9155 & 42.65 \\
2013 & $14,449.904$ & $22,898,810$ & 9100 & 46.47 \\
2014 & $15,672.893$ & $26,089,057$ & 9515.34 & 50.54 \\
2015 & $16,803.12$ & $29,534,213$ & 9761 & 59.9 \\
2016 & $18,317.64$ & $34,491,858$ & 10,092 & 62.06 \\
\hline
\end{tabular}




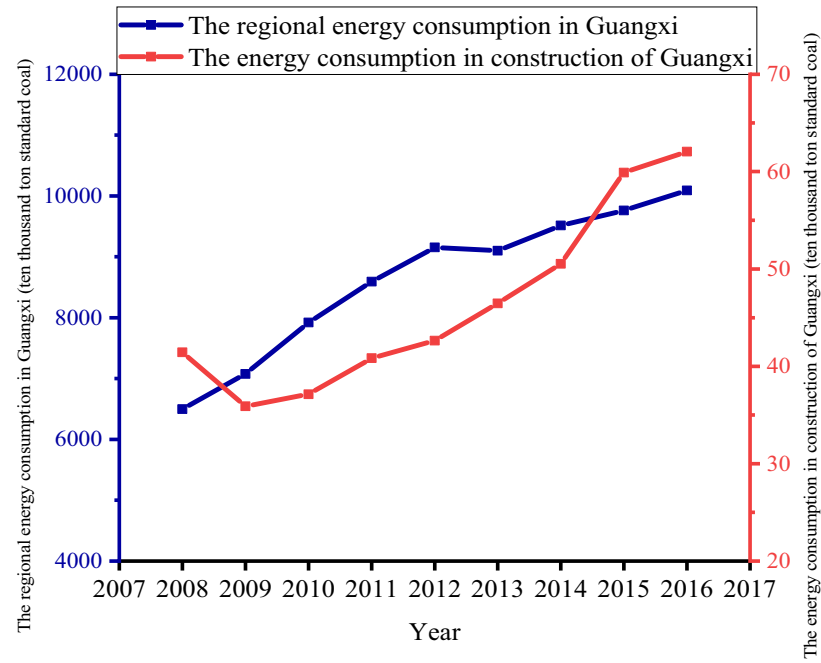

Fig. 3 Line chart of the regional energy consumption and energy consumption in the construction industry of Guangxi from 2008 to 2016

Tapio model for further analysis, the following decoupling evaluation data are presented, which are contrasted to the decoupling states of the Tapio model, as summarized in Table 1.

As indicated in Table 5, the decoupling relationship between the energy consumption in the Guangxi construction industry and its output level is determined based on 2008 data, revealing a weak decoupling relationship from 2010 to 2016. In particular, with increasing energy consumption in the Guangxi construction industry, the output level also increases year by year. However, the increase in the output level of the Guangxi construction industry is more substantial than the increase in the energy consumption in the construction industry, indicating that the output level increase of the Guangxi construction industry is not entirely dependent on the energy consumption rise. Moreover, the decoupling coefficient shows a decrease trend year by year from 2010 to 2016 . According to the definition of the energy
Table 5 List of the decoupling elasticity coefficients of the construction industry economic growth against the construction industry energy consumption from 2008 to 2016

Year $M \quad \begin{aligned} & \text { El (10 thousand } \\ & \text { tonnes standard } \\ & \text { coal) }\end{aligned} \quad$ Gl (10 thousand RMB) $\quad$ ED

\begin{tabular}{lllll}
\hline 2008 & 1.00 & - & - & - \\
2009 & 0.70 & $-5.55(-)$ & $1,811,654(+)$ & \\
2010 & 0.55 & $1.24(+)$ & $2,879,370(+)$ & $\begin{array}{c}\text { Weak } \\
\text { decou- } \\
\text { pling } \\
\text { Weak }\end{array}$ \\
2011 & 0.48 & $3.69(+)$ & $3,307,586(+)$ & Weak \\
2012 & 0.42 & $1.82(+)$ & $3,139,868(+)$ & Weak \\
2013 & 0.37 & $3.82(+)$ & $4,228,230(+)$ & Weak \\
2014 & 0.35 & $4.07(+)$ & $3,190,247(+)$ & Weak \\
2015 & 0.37 & $9.36(+)$ & $3,445,156(+)$ & Weak \\
2016 & 0.33 & $2.16(+)$ & $4,957,645(+)$ &
\end{tabular}

decoupling coefficient of the construction industry, compared to the Tapio decoupling model, it is found that the elastic coefficient approaches 0 , and a strong decoupling trend is indicated when the energy consumption and output level increase related to this coefficient are both definite. According to the definition of decoupling, the optimal state is attained when the output of the construction industry increases but the energy consumption decreases, and the decoupling coefficient is smaller than 0 . Therefore, it can be inferred that the relationship between the energy consumption and output level of the Guangxi construction industry is being developed in a sustainable manner. Nevertheless, it is worth noting that in 2009, the Guangxi construction industry energy consumption decreased 55,500 tonnes of standard coal, while the construction industry output level increased 18.11654 billion yuan. With the dimensionless calculation equation, the decoupling coefficient is 0.7 , which is higher than that of the increasing energy consumption and construction industry output from 2010 to 2016.
Table 4 List of the decoupling elasticity coefficients of the economic growth, construction industry output increase and energy consumption in Guangxi Province from 2008 to 2016

\begin{tabular}{llllllll}
\hline Year & $\mathrm{Gl}$ & $\mathrm{Gl}_{J}$ & $\mathrm{El}$ & $\mathrm{El}_{J}$ & $M$ & $N$ & $\mathrm{DE}$ \\
\hline 2008 & 1.00 & 1 & 1.00 & 1.00 & 1.00 & 1.00 & 1.00 \\
2009 & 1.11 & 1.25 & 1.09 & 0.87 & 0.70 & 0.99 & 0.78 \\
2010 & 1.36 & 1.62 & 1.22 & 0.90 & 0.55 & 0.89 & 0.66 \\
2011 & 1.67 & 2.06 & 1.32 & 0.99 & 0.48 & 0.79 & 0.59 \\
2012 & 1.86 & 2.48 & 1.41 & 1.03 & 0.42 & 0.76 & 0.55 \\
2013 & 2.06 & 3.04 & 1.40 & 1.12 & 0.37 & 0.68 & 0.54 \\
2014 & 2.23 & 3.46 & 1.46 & 1.22 & 0.35 & 0.66 & 0.55 \\
2015 & 2.39 & 3.92 & 1.50 & 1.45 & 0.37 & 0.63 & 0.60 \\
2016 & 2.61 & 4.58 & 1.55 & 1.50 & 0.33 & 0.60 & 0.57 \\
\hline
\end{tabular}


Table 6 The decoupling elasticity coefficient of the energy consumption from the economic growth of the Guangxi Province construction industry in 2009

\begin{tabular}{lllll}
\hline Year & $\begin{array}{l}\text { Energy } \\
\text { decoupling } \\
\text { elasticity } \\
\text { coefficient } M\end{array}$ & $\begin{array}{l}\text { Ratio of } \\
\text { energy con- } \\
\text { sumption }\end{array}$ & $\begin{array}{l}\text { Ratio of } \\
\text { economic } \\
\text { growth }\end{array}$ & $\begin{array}{l}\text { Evaluation of } \\
\text { decoupling } \\
\text { state }\end{array}$ \\
\hline 2009 & -0.56 & $13.39 \%(-)$ & $24.00 \%(+)$ & $\begin{array}{l}\text { Strong } \\
\text { decoupling }\end{array}$ \\
\hline
\end{tabular}

This shows that the calculation of the decoupling coefficient is more impacted in terms of the relative value rather than the absolute value for a particular year. For this specific case in 2009 , under the basic definition of the unified decoupling models for the various data types with different units, different rates are obtained with the original data.

In 2009, there existed a strong decoupling relation between the decrease in energy consumption and the increase in output level of the Guangxi construction industry, as shown in Table 6.
Referring to Tables 7 and 8, in 2009, the construction industry energy consumption in Guangxi is 55,500 tonnes of standard coal lower than that of the previous year, while the regional economy increases 73.816 billion yuan. Through the dimensionless calculation equation, the decoupling coefficient is 0.8 , which is higher than the decoupling coefficient of the increase in construction industry energy consumption and total power generation from 2010 to 2016. These results demonstrate that for any given year, the calculation of the decoupling coefficient is affected more by the relative value rather than by the absolute value. For the unique case of 2009, the different ratios are obtained with the original data under the basic definition of the decoupling model unifying the units of the different data types.

Table 9 indicates the active decoupling state of the energy consumption in the construction industry relative to its growth based on the decrease in energy consumption in the construction industry relative to the GDP in 2009. In addition, the absolute value of the industrial decoupling energy coefficient $(-1.27)$ is higher than that of the decoupling energy elasticity coefficient of
Table 7 List of the decoupling elasticity coefficients of the economic growth of the construction industry from the economic growth of Guangxi Province from 2008 to 2016

\begin{tabular}{lllll}
\hline Year & $\begin{array}{l}\text { Decoupling } \\
\text { elasticity coef- } \\
\text { ficient } N\end{array}$ & $\begin{array}{l}\text { Economic growth of the con- } \\
\text { struction industry (10 thousand } \\
\text { RMB) }\end{array}$ & $\begin{array}{l}\text { Economic growth } \\
(100 \text { million RMB) }\end{array}$ & $\begin{array}{l}\text { Evaluation of the } \\
\text { decoupling state }\end{array}$ \\
\hline 2008 & 1.00 & - & - & - \\
2009 & 0.99 & $1,811,654(+)$ & $738.16(+)$ & Growing connection \\
2010 & 0.89 & $2,879,370(+)$ & $1810.69(+)$ & Growing connection \\
2011 & 0.79 & $3,307,586(+)$ & $2151.02(+)$ & Weak \\
2012 & 0.76 & $3,139,868(+)$ & $1314.232(+)$ & Weak \\
2013 & 0.68 & $4,228,230(+)$ & $1414.802(+)$ & Weak \\
2014 & 0.66 & $3,190,247(+)$ & $1222.989(+)$ & Weak \\
2015 & 0.63 & $3,445,156(+)$ & $1130.227(+)$ & Weak \\
2016 & 0.60 & $4,957,645(+)$ & $1514.52(+)$ & Weak \\
\hline
\end{tabular}

Table 8 List of the decoupling elasticity coefficients of the energy consumption against the economic growth of the construction industry of Guangxi Province from 2008 to 2016

\begin{tabular}{lllll}
\hline Year & $\begin{array}{l}\text { Industrial energy decou- } \\
\text { pling coefficient DE }\end{array}$ & $\begin{array}{l}\text { Energy consumption growth of the construction } \\
\text { industry (10 thousand tonnes standard coal) }\end{array}$ & $\begin{array}{l}\text { Economic growth } \\
(100 \text { million) }\end{array}$ & $\begin{array}{l}\text { Evaluation of the } \\
\text { decoupling state }\end{array}$ \\
\hline 2008 & 1.00 & - & - & $738.16(+)$ \\
2009 & 0.78 & $-5.55(-)$ & $1810.69(+)$ & Weak \\
2010 & 0.66 & $1.24(+)$ & $2151.02(+)$ & Weak \\
2011 & 0.59 & $3.69(+)$ & $1314.232(+)$ & Weak \\
2012 & 0.55 & $1.82(+)$ & $1414.802(+)$ & Weak \\
2013 & 0.54 & $3.82(+)$ & $1222.989(+)$ & Weak \\
2014 & 0.55 & $4.07(+)$ & $1130.227(+)$ & Weak \\
2015 & 0.60 & $9.36(+)$ & $1514.52(+)$ & Weak \\
2016 & 0.57 & $2.16(+)$ & &
\end{tabular}


Table 9 The decoupling elasticity coefficient of the energy consumption in the construction industry against the economic growth of Guangxi in 2009

\begin{tabular}{lllll}
\hline Year & $\begin{array}{l}\text { Industrial } \\
\text { energy } \\
\text { decoupling } \\
\text { coefficient DE }\end{array}$ & $\begin{array}{l}\text { Ratio of the } \\
\text { energy con- } \\
\text { sumption in } \\
\text { the construc- } \\
\text { tion industry } \\
\text { (10 thousand } \\
\text { tonnes stand- } \\
\text { ard coal) }\end{array}$ & $\begin{array}{l}\text { Ratio of the } \\
\text { growth (100 }\end{array}$ & $\begin{array}{l}\text { Evaluation of } \\
\text { me decou- } \\
\text { pling state }\end{array}$ \\
\hline $2009-1.27$ & $13.39 \%(-)$ & $10.51 \%(+)$ & strong \\
\hline
\end{tabular}

the construction industry $(-0.56)$, which shows that the marginal benefits to the regional economy due to the energy consumption increase are superior to those due to the industrial economic growth. However, it cannot be asserted that increasing the GRP is more effective than promoting the regional construction industry output level, and the relationship between the local construction industry output level and total investments should be considered. By analysing the data in Table 7, the relationship between these two aspects is a trend of mutual increase, which definitely plays a promoting role in the growth of indicators due to the increase in other indicators, and it can be concluded that the increase in the output level of the Guangxi construction industry enhances the GRP of Guangxi.

\subsection{Analysis of the decoupling of the energy consumption in the construction industry from the regional economic growth}

After calculations with and modification of the above data, the analysis results based on the data in Tables 3, 4, 5, 6, 7, 8 and 9 are as follows:

1. From 2008 to 2016, except for the reduction in the energy consumption in the construction industry in 2009 and the economic growth in Guangxi, the industrial energy decoupling coefficient was -1.27 , which was the only negative value in the nine years. In the other years, the decoupling coefficient was between 0 and 0.8 based on the 2008 data, indicating a weak decoupling effect, and the industrial energy decoupling coefficient decreased year by year. From the data analysis in Table 10 and Fig. 4, it can be concluded that the construction industry has an increasing influence on the regional economic development. Moreover, the growth rate of energy consumption is lower than that of the industrial and regional economic output levels, indicating that the economic growth of Guangxi is
Table 10 Ratio of the output level of the Guangxi construction industry to the GRP from 2008-2016

\begin{tabular}{cclcc}
\hline Year & $\begin{array}{l}\text { GRP in construc- } \\
\text { tion (10 thousand } \\
\text { RMB) }\end{array}$ & $\begin{array}{l}\text { GRP (100 million } \\
\text { RMB) }\end{array}$ & Percentage & Trend \\
\hline 2008 & $7,532,102$ & 7021 & 10.73 & $(+)$ \\
2009 & $9,343,756$ & 7759.16 & 12.04 & $(+)$ \\
2010 & $12,223,126$ & 9569.85 & 12.77 & $(+)$ \\
2011 & $15,530,712$ & $11,720.87$ & 13.25 & $(+)$ \\
2012 & $18,670,580$ & $13,035.102$ & 14.32 & $(+)$ \\
2013 & $22,898,810$ & $14,449.904$ & 15.85 & $(+)$ \\
2014 & $26,089,057$ & $15,672.893$ & 16.65 & $(+)$ \\
2015 & $29,534,213$ & $16,803.12$ & 17.58 & $(+)$ \\
2016 & $34,491,858$ & $18,317.64$ & 18.83 & $(+)$ \\
\hline
\end{tabular}

gradually becoming independent of the energy consumption in the Guangxi construction industry.

2. Table 4 indicates that from 2008 to $2016, M$, the energy decoupling elasticity coefficient was between 0 and 1 , in addition to $N$, the industrial decoupling elasticity coefficient, and $\mathrm{DE}$, the industrial energy decoupling coefficient of the construction industry, and these three indexes exhibited a decrease trend year by year. The relationship among them is shown in Fig. 5:

From Fig. 5, the trend of the three indexes is basically consistent, which illustrates a good coupling degree and correlation. The construction energy decoupling coefficient decreases more notably than the other two indexes, implying that the energy consumption increases the least. Therefore, the increase in construction industry output level and regional economy is not entirely dependent on the increase in energy consumption.

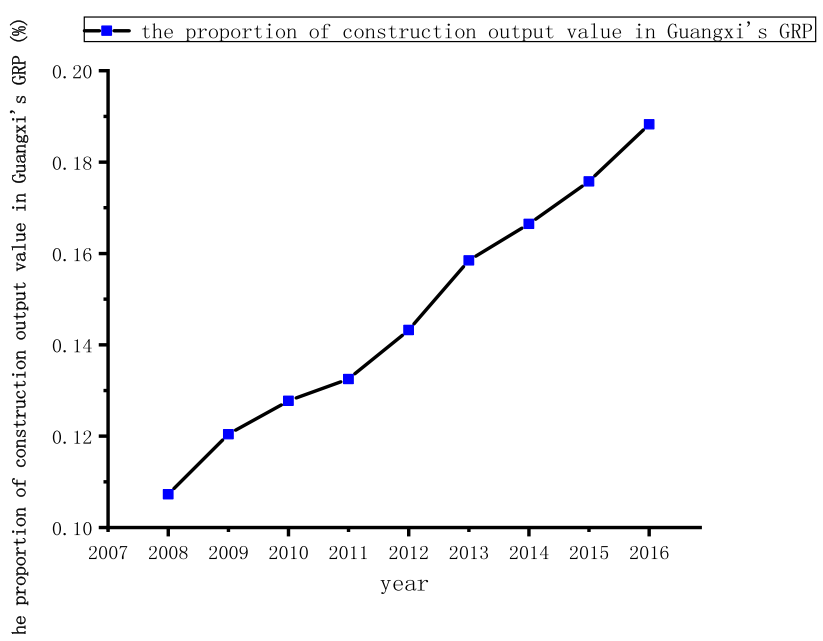

Fig. 4 Trend chart of the proportion of the construction industry output level in the GRP of Guangxi from 2008 to 2016 


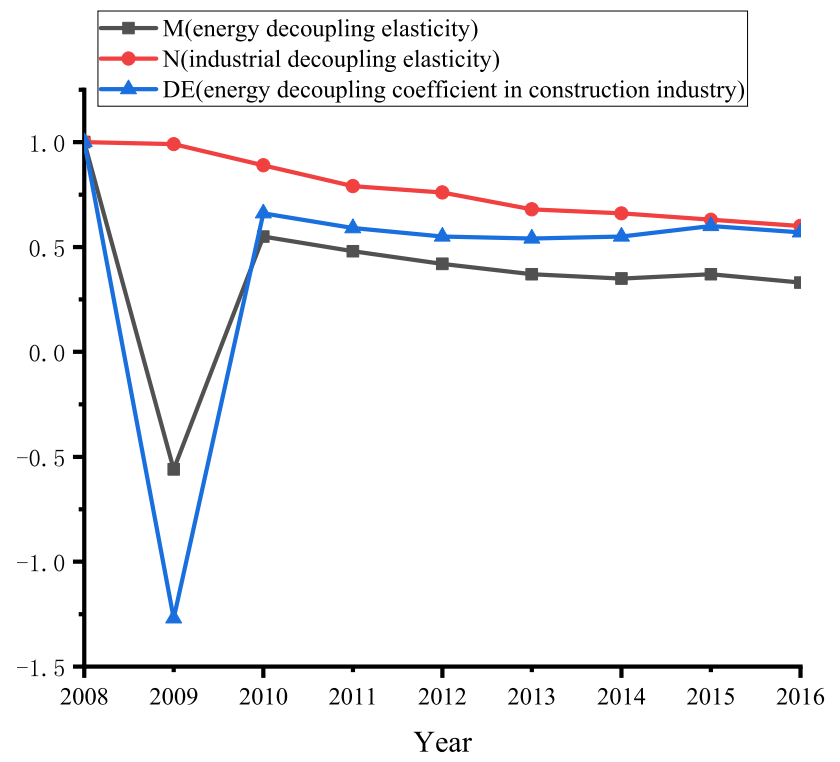

Fig. 5 Comparison of the trends of $M$, the energy decoupling elasticity coefficient, $\mathrm{N}$, the industrial decoupling elasticity coefficient, and $\mathrm{DE}$, the construction industry energy decoupling coefficient, from 2008 to 2016

3. In 2009 , the negative coefficient of $M$, the decoupling elasticity coefficient of the construction industry energy consumption, and the decoupling coefficient of the overall industry energy consumption all indicated robust decoupling effects, while the decoupling coefficient of the industrial energy consumption was more notable than the former. Therefore, it can be concluded that although the proportion of the construc- tion industry output in the total economic output has increased after 2009, the increase in energy consumption has substantially decreased. The industrial output level and district economy have improved dramatically, which conforms to the ideal state in the Tapio model. In 2009, good results have been obtained in controlling the Guangxi construction industry energy consumption, thus achieving the goal of sustainable development.

\subsection{Ecological efficiency evaluation of the construction industry}

The concept of the ecological efficiency (Schaltegger, 1990) was utilized in the earliest circular economy assessment. In 1998, the Organization for Economic Cooperation and Development (OECD) defined the ecological efficiency of ecological resources in satisfying human needs, which is a form of the output-input ratio. Consequently, the data in Table 11 were classified and defined, and the resource costs were established, including the energy and economic costs, after considering the OECD definition of the ecological efficiency. The resource output includes the GDP (yuan) per tonne of energy consumption and the investments in pollution control projects completed in a given year (10 thousand yuan). Based on the above considerations, the circular economy system evaluation index of the value stream can be deconstructed according to the characteristics of the construction industry, as summarized in Table 11.
Table 11 Production efficiency evaluation index table

\begin{tabular}{|c|c|c|c|c|}
\hline \multirow[t]{2}{*}{ Year } & \multicolumn{2}{|l|}{ Resource input } & \multicolumn{2}{|l|}{ Resource output } \\
\hline & energy cost (EI) & $\begin{array}{l}\text { production cost (PI) } \\
\text { (10 thousand yuan) }\end{array}$ & $\begin{array}{l}\text { GRP/energy con- } \\
\text { sumption per tonne } \\
\text { (yuan) }\end{array}$ & $\begin{array}{l}\text { Investments in pollution } \\
\text { control projects ( } 10 \text { thousand } \\
\text { yuan) }\end{array}$ \\
\hline 2008 & 41.45 & $6,661,335$ & 10,806 & 149,751 \\
\hline 2009 & 35.9 & $8,249,579$ & 10,967 & 117,118 \\
\hline 2010 & 37.14 & $10,605,139$ & 12,000 & 92,845 \\
\hline 2011 & 40.83 & $12,778,993$ & 13,643 & 129,745 \\
\hline 2012 & 42.65 & $14,623,569$ & 15,280 & 127,329 \\
\hline 2013 & 46.47 & $18,397,299$ & 15,799 & 183,218 \\
\hline 2014 & 50.54 & $21,417,909$ & 16,156 & 178,909 \\
\hline 2015 & 59.9 & $23,553,984$ & 17,215 & 247,151 \\
\hline 2016 & 62.06 & $25,954,335$ & 18,078 & 130,442 \\
\hline
\end{tabular}

The above data are all collected within the Guangxi construction industry. The energy cost refers to the energy consumption in the Guangxi construction industry (in ten thousand tonnes of standard coal). In the statistics of Guangxi, the GRP (yuan) realized by the energy consumption per tonne and the investment amount in pollution control projects completed in a given year are not included in the list. The percentage of the aggregate data in the Guangxi Statistical Yearbook is separately accounted for. In the statistical data, the production cost data for 2008 are missing. Through data comparison, it is found that the data from 2005 to 2016 show linear characteristics. Therefore, the linear interpolation method is applied to calculate the data for 2008 
Table 12 Efficiency index of the dimensionless ecological evaluation

\begin{tabular}{|c|c|c|c|c|}
\hline \multirow[t]{2}{*}{ Year } & \multicolumn{2}{|l|}{ Resource input } & \multicolumn{2}{|l|}{ Resource output } \\
\hline & Energy cost (El) & $\begin{array}{l}\text { Production } \\
\text { cost (PI) }\end{array}$ & $\begin{array}{l}\text { GRP/energy consump- } \\
\text { tion per tonne (yuan) }\end{array}$ & $\begin{array}{l}\text { Investments in pollution } \\
\text { control projects ( } 10 \text { thousand } \\
\text { yuan) }\end{array}$ \\
\hline 2008 & 1.00 & 1.00 & 1.00 & 1.00 \\
\hline 2009 & 0.87 & 1.24 & 1.01 & 0.78 \\
\hline 2010 & 0.90 & 1.59 & 1.11 & 0.62 \\
\hline 2011 & 0.99 & 1.92 & 1.26 & 0.87 \\
\hline 2012 & 1.03 & 2.20 & 1.41 & 0.85 \\
\hline 2013 & 1.12 & 2.76 & 1.46 & 1.22 \\
\hline 2014 & 1.22 & 3.22 & 1.50 & 1.19 \\
\hline 2015 & 1.45 & 3.54 & 1.59 & 1.65 \\
\hline 2016 & 1.50 & 3.90 & 1.67 & 0.87 \\
\hline
\end{tabular}

Table 13 Eco-efficiency from 2008 to 2016

\begin{tabular}{llllllllll}
\hline Year & 2008 & 2009 & 2010 & 2011 & 2012 & 2013 & 2014 & 2015 & 2016 \\
\hline EE & 0.1073 & 0.1028 & 0.0888 & 0.0972 & 0.1006 & 0.1096 & 0.1010 & 0.11145 & 0.0888 \\
\hline
\end{tabular}

\section{Conclusions and policy recommendations}

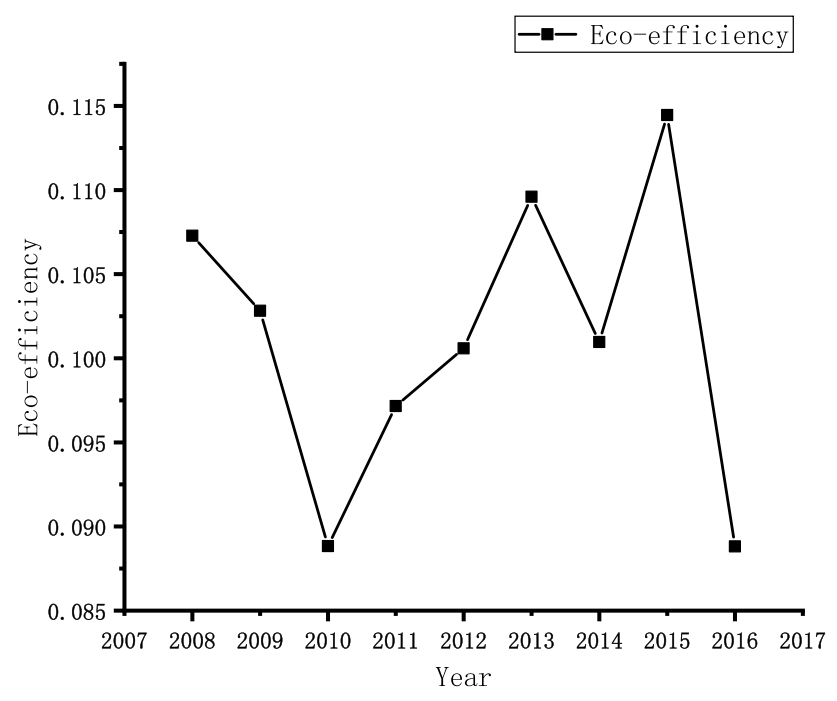

Fig. 6 Line chart of the Guangxi construction industry energy cycle production efficiency from 2009 to 2016

For the purpose of correcting the differences between the different units and facilitating calculations, the data of 2008-2016 are nondimensionalized based on the data of 2008, and Table 12 is thus obtained.

According to Eqs. 3-6, the energy cycle production efficiency of the construction industry in each year from 2008 to 2016 is calculated, as summarized in Table 13 and shown in Fig. 6.

\subsection{Conclusions}

By evaluating the data of the energy cycle production efficiency and decoupling coefficient of the Guangxi construction industry from 2008 to 2016, the following conclusions can be drawn regarding the energy consumption and the economic growth of the Guangxi construction industry from the perspective of the circular economy, as summarized in Table 14.

The ecological efficiency value of 0.490 from 2006 to 2015 in Guangxi is based on the evaluation and research on the influencing factors of the regional economic and ecological efficiencies conducted by Guo and Huang [32]. However, in this paper, the ecological efficiency value from 2009 to 2016 is 0.1012 . It can be concluded that the level of circular economic development of the Guangxi construction industry is lower than the average level of other industries, and the Guangxi circular economy still has much room for improvement.

From 2009 to 2016, the energy consumption in the construction industry of Guangxi exhibited a weak decoupling from the economic growth of the region, which indicates that the economic growth had a slightly negative impact on the energy consumption. Especially in 2009, strong decoupling occurred, in which the economic growth in that year was not wholly dependent on the energy consumption, basically reaching the ideal decoupling state. However, the ecological efficiency was very low in 2009. In the process of energy consumption, 
Table 14 Guangxi construction industry circular economy evaluation

\begin{tabular}{lllll}
\hline Year & $\begin{array}{l}\text { Industrial energy } \\
\text { decoupling coefficient } \\
\text { DE }\end{array}$ & $\begin{array}{l}\text { Evaluation of the } \\
\text { decoupling state }\end{array}$ & $\begin{array}{l}\text { Production } \\
\text { efficiency }\end{array}$ & Circular economy assessment \\
\hline 2008 & 1.00 & - & - & - \\
2009 & -1.27 & Strong & 0.1028 & Relatively low circular efficiency \\
2010 & 0.66 & Weak & 0.0888 & Low \\
2011 & 0.59 & Weak & 0.0972 & Low \\
2012 & 0.55 & Weak & 0.1006 & Relatively low \\
2013 & 0.54 & Weak & 0.1096 & Relatively low \\
2014 & 0.55 & Weak & 0.1010 & Relatively low \\
2015 & 0.60 & Weak & 0.1145 & Relatively low \\
2016 & 0.57 & Weak & 0.0888 & Low \\
\hline
\end{tabular}

sustainable development had not yet achieved the perfect cycle of energy consumption reduction, reuse, and recycling. The production efficiency in the other years is generally lower than 0.2 , and only the production efficiency in 2013 is slightly higher than 0.2, which is the peak value in the 8-year period. Moreover, in addition to attaining the lowest value, the energy decoupling coefficient analysis reveals that the decoupling and cycle efficiency are both optimal in 2009. In 2016, the production efficiency is $10 \%$ lower than that in the previous year and $7 \%$ lower than the average value, which is the lowest value in this eight-year period. At the same time however, it is found that the decoupling coefficient in that year is close to the value in previous years. Although there is no distinct connection between the regional economic growth and construction industry energy consumption growth, the recycling efficiency has steeply decreased, and no energy recovery and sustainable construction industry development occur in 2016.

On the whole, the Tapio model examines the decoupling effect between the Guangxi construction industry energy consumption growth and regional economic growth. Based on the Guangxi decoupling coefficient, Guangxi does not rely on industrial energy consumption to drive the regional economy. Combined with the production efficiency index calculated from the perspective of the circular economy, it is concluded that the energy recycling efficiency of the Guangxi construction industry is very low, and the energy sustainable utilization capacity is insufficient.

\subsection{Policy recommendations}

Based on the dimensionless data from 2008 to 2016, this paper calculated the decoupling coefficient and production efficiency from 2009 to 2016 and evaluated the decoupling effect and production efficiency. In this section, specific suggestions are proposed:
1. Prioritizing the development of the construction industry and strengthening its pillar role

Based on the above data and indices, the development of the construction industry in Guangxi increases year by year. Its role in promoting the economic development of Guangxi is very clear. With the development of the economy of Guangxi and the need for urban infrastructure construction, the proportion of the Guangxi construction industry in the regional economic output will gradually increase. Despite the increasing concerns about its benign development and pillar role, the construction industry has an essential impact on the economic development of Guangxi.

2. Increasing the economic input and promoting industrial upgrading

We find that the Guangxi construction industry is rapidly developing with a low energy cycle efficiency, which is at the moderate-low level in China based on data computation. From the assessment of the ecological evaluation system, Guangxi has a moderate to high ecological efficiency at present. The economic development of Guangxi should be realized not only by improving the economic indicators but also by optimizing the ecological indicators. As a tourism province, the development of Guangxi should rely on the protection and sustainable development of its ecological resources. For the sake of developing the Guangxi construction industry in a virtuous cycle of low energy consumption and high output, the outdated production capacity should be actively eliminated, economic investments should be increased, construction industry upgrading should be promoted and the energy cycle efficiency of the Guangxi construction industry should be improved.

3. Strengthening the awareness of sustainable development and establishing the ideas of the circular economy 
For the construction industry, we should attach importance to policy guidance and standardize the green construction, energy conservation and emission reduction measures of construction-related enterprises by establishing relevant industry standards. In addition, the release of policy documents encourages construction-related enterprises to save energy and reduce emissions and promotes technological upgrading and transformation.

Acknowledgements The authors acknowledge the financial support from the 2017 Shaanxi Social Science Funds Program, Research on the Development Mode and Compensation Mechanism of the Circular Economy Industrial Cluster in Southern Shaanxi (Grant No. 2017S014)/Shaanxi Soft Science Research Program (Joint Project) Efforts to Promote the Construction of the Whole Industrial Chain and Acceleration of the Construction of the Green Circular Industry System (Grant No. 2018KRLY20)/2018 Guangxi's Middle and Young Teachers Basic Ability Improvement Project: Application and Practice of BIM in Information Treatment of Quality Control in Assembly Construction (Grant No. 2018KY1010).

Author contributions All authors contributed to the study conception and design. Material preparation, data collection and analysis were performed by $\mathrm{XL}, \mathrm{FL}$ and $\mathrm{CP}$. The first draft of the manuscript was written by $\mathrm{XL}$, and all authors commented on previous versions of the manuscript. All authors read and approved the final manuscript.

Data availability All data, models, and code generated or used during the study appear in the submitted article.

\section{Compliance with ethical standards}

Conflict of interest The authors declare that they have no conflicts of interest.

Availability of data and materials The data sets supporting the results of this article are included within the article and its additional files.

\section{References}

1. The Belt and Road Initiative for Green Development Publishing China Economic Net. https://district.ce.cn/newarea/roll/20180 8/01/t20180801_29910677.shtml. Accessed 10 June 2019.

2. Feng $B$, Wang $X$ (2015) Study on the decoupling of carbon emissions in construction industry of Chinese Provinces and the influencing factors. China Popul Resour Environ 25:28-34. https://doi.org/10.3969/j.issn.1002-2104.2015.04.004

3. Soytas U, Sari R (2009) Energy consumption, economic growth, and carbon emissions: challenges faced by an EU candidate member. Ecol Econ 68:1667-1675. https://doi.org/10.1016/j. ecolecon.2007.06.014

4. Ghosh S (2009) Electricity supply, employment and real GDP in India: evidence from cointegration and Granger-causality tests. Energy Policy 37:2926-2929. https://doi.org/10.1016/j.enpol .2009.03.022

5. Khan I (2019) Power generation expansion plan and sustainability in a developing country: a multi-criteria decision analysis. J Clean Prod 220:707-720. https://doi.org/10.1016/j.jclep ro.2019.02.161
6. Balsalobre-Lorente D, Shahbaz M, Roubaud D, Farhani S (2018) How economic growth, renewable electricity and natural resources contribute to $\mathrm{CO}_{2}$ emissions? Energy Policy 113:356367. https://doi.org/10.1016/j.enpol.2017.10.050

7. Wang S, Li C, Yang L (2018) Decoupling effect and forecasting of economic growth and energy structure under the peak constraint of carbon emissions in China. Environ Sci Pollut Res Int 25:25255-25268. https://doi.org/10.1007/s11356-018-2520-2

8. Mohiuddin O, Asumadu-Sarkodie S, Obaidullah M (2016) The relationship between carbon dioxide emissions, energy consumption, and GDP: a recent evidence from Pakistan. Cogent Eng 3:1210491. https://doi.org/10.1080/23311916.2016.12104 91

9. Destek MA, Sarkodie SA (2019) Investigation of environmental Kuznets curve for ecological footprint: the role of energy and financial development. Sci Total Environ 650:2483-2489. https ://doi.org/10.1016/j.scitotenv.2018.10.017

10. Sarkodie SA, Strezov V (2019) A review on environmental Kuznets curve hypothesis using bibliometric and meta-analysis. Sci Total Environ 649:128-145. https://doi.org/10.1016/j.scito tenv.2018.08.276

11. Bekun FV, Alola AA, Sarkodie SA (2019) Toward a sustainable environment: nexus between $\mathrm{CO}_{2}$ emissions, resource rent, renewable and nonrenewable energy in 16-EU countries. Sci Total Environ 657:1023-1029. https://doi.org/10.1016/j.scito tenv.2018.12.104

12. Sarkodie SA, Strezov V (2019) Economic, social and governance adaptation readiness for mitigation of climate change vulnerability: evidence from 192 countries. Sci Total Environ 656:150164. https://doi.org/10.1016/j.scitotenv.2018.11.349

13. Bekun FV, Emir F, Sarkodie SA (2019) Another look at the relationship between energy consumption, carbon dioxide emissions, and economic growth in South Africa. Sci Total Environ 655:759-765. https://doi.org/10.1016/j.scitotenv.2018.11.271

14. Hu Z, Liu Y, Tang L (2012) An empirical study of the relationship between energy consumption, carbon emissions, and economic growth in China. Technol Hum Univ Nat Sci 39:84-88. https:// doi.org/10.3969/j.issn.1674-2974.2012.07.016

15. Zhang S, Tang X (2014) Relationship between carbon emissions and economic growth in construction industry of Shaanxi Province. Ind Eng J 17:68-72. https://doi.org/10.3969/j. issn.1007-7375.2014.03.013

16. Feng $B$, Wang $X$ (2015) Research on carbon decoupling effect and influence factors of provincial construction industry in China. China Popul Resour Environ 25(4):28-34. https://doi. org/10.3969/j.issn.1002-2104.2015.04.004

17. Chu D, Shoufeng $Q$ (2006) Eco-efficiency is an appropriate measure of the circular economy. China Popul Resour Environ 16:1-6. https://doi.org/10.3969/j.issn.1002-2104.2006.05.001

18. Deng H, Duan N (2004) Decoupling evaluation model and its impact on the circular economy. China Popul Resour Environ. https://doi.org/10.3969/j.issn.1002-2104.2004.06.009

19. Li Y, Li Z, You H (2016) The circular economic development level of Beijing's service sector based on AHP modeling. J Resour Ecol 7:480-485. https://doi.org/10.5814/j.issn.1674-764x.2016.06.008

20. Wang $X$ (2003) Research on basic ways and countermeasures of developing circular economy. Soft Sci. https://doi.org/10.3969/j. issn.1001-8409.2003.01.008

21. Zhong T, Huang X, Li L, Wang C (2006) Assessing regional circular economy development: approaches and indicator systems: a case study in Jiangsu province. Resour Sci. https://doi. org/10.3321/j.issn:1007-7588.2006.02.023

22. Lizhi Z (2017) Theoretical viewpoint on value-increasing of circular economy-study based on the practice of circular agriculture. Asian Agric Res 9:1-5. https://doi.org/10.22004/ ag.econ. 262765 
23. Wang Y (2016) Research of factors impact on development mode in construction industry. Dissertation, Harbin Institute of Technology. https://doi.org/10.7666/d.D01102746

24. Wang X, Lou X, Yang Q (2012) Inter-provincial difference in energy efficiency of construction industry and its influencing factors in China. China Popul Resour Environ 22(2):56-61. https ://doi.org/10.3969/j.issn.1002-2104.2012.02.009

25. Yu F (2015) Review and prospect of China's eco-industrial development policy. Social Scientist 10:7-13. https://doi. org/10.3969/j.issn.1002-3240.2015.10.002

26. Zhou Z, Zhang L, Ou J (2018) Research on optimization of circulating economic value flow in process-based manufacturing enterprises-take papermaking enterprises as an example. Acc Finance. https://doi.org/10.3969/j.issn.1674-3059.2018.05.015

27. Wang J (2016) Technology innovation capacity evaluation of circular economy in China's steel industry. Sci Technol Manag Res 36(20):117-122. https://doi.org/10.3969/j. issn.1000-7695.2016.20.022

28. OECD (2002) Indicators to measure decoupling of environmental pressures from economic growth. OECD, Paris
29. Tapio $P$ (2005) Towards a theory of decoupling: degrees of decoupling in the EU and the case of road traffic in Finland between 1970 and 2001. Transp Policy 12:137-151. https://doi. org/10.1016/j.tranpol.2005.01.001

30. China Statistical Yearbook (2017). https://www.stats.gov.cn/tjsj/ ndsj/2017/indexch.htm. Accessed 5 May 2020

31. Development Planning of Guangxi Beibu Gulf Economic Zone Publishing people's daily online. https://gx.people.com. cn/n/2015/0522/c371361-24965939.html. Accessed 10 June 2019

32. Guo X, Huang S (2018) Evaluation of eco-efficiency of the regional economy and its influencing factors. Contemp Econ. https://doi.org/10.3969/j.issn.1007-9378.2018.15.022

Publisher's Note Springer Nature remains neutral with regard to jurisdictional claims in published maps and institutional affiliations. 